\section{Special Solar Heat-Radiations and their Earth-felt Effects}

THE well-filled lectures on Solar Physics by Prof, Balfour Stewart, published in NATURE, vol. xxiv. pp. I14, 150, will undouttedly promote the study and assist the understanding of those subjects; and if a single one of the many items alluded to was not quite correctly described, that is neither surprising in itself nor likely to do much harm amidst the wealth of information which was at the same time both correctly stated and neatly conveyed. I should not therefore think myself now called on to notice one exceptional paragraph, but that it contains a most singular mistake in attributing to me conclusions from my own Edinburgh observations that are the very opposite of what I have often published between 1869 and the present time. Nor do I propose to make any positive complaint ; for I rather admire the honesty of the lecturer who, after arguing for the rore spotted fericds of the sun's disk being its occasions of strongest heat evolutions, yet stated voluntarily and against himself that a directly opposite conclusion to his had been deduced by me from the unrivalled collection of more than thirty years of rockthermometer observations on the Calton Hill. That is to say, that a certain eleven-year heat-wave shown by those thermometers coincided with, not the maximum, but the minimum spotted state of the sun; subject however to what the lecturer termed "a slight," but in reality a two or three year "lagging behind" the visible solar phenomenon.

Now let the sun, at any short-lived epoch, give forth an extra radiation of heat: I cannot imagine any person attempting or expecting to find its effects, after two or three years, as an acutely marked phenomenon in daily air and superficial earthtemperature otservations. When therefore a very sharp phenomenon was marked on, or by, our thermometers, I looked for its explanation, not to what had occurred and passed away again several years before, but to something in nearly simultanecus progress on the sun. This something ton, which I held forth upon even in my first paper on the subject in 1869 to the Royal Society, was ready at hand as a vera causa; and I ventured to descrite it as "the ascending node" of the eleven-year sun-spot curve, or the time when a new cycle of sun-spots is not only well begun, but is in the act of its most rapid increase for any part of the cycle; just as a soda-water bottle effervesces most violently immediately after it is uncorked, rather than long afterwards, when some of its slowly-formed last bubbles are quietly escaping, and much more so than when it is not uncorked at all. In a letter too, printed in NATURE not two years ago, I showed how a great part of the solar action might be, and even had been immediate on our thermometers, in consequence of the very first action of a renovated sun, being a dispersion of the ordinary clouds in silu, whence an extra amount of direct sun hine on the earth teneath them, producing a dry hot year to the agriculturists there.

The second effects I also showed might be an increased evaporation of distant ocean-surface; the formation thereby and bring. ing round of greater clouds, heavy rain, and precisely the cold seasons which our Edinburgh thermometers had : hown, throngh thirty years, did generally follow the eleven-year wave of heat. Not, evidently, that the sun was then at a minimum of heat radiation, but that a creen of wet clouds had been drawn between it and that part of the earth where observations were going on.

Now something like this whole sequence of effects has just keen experienced in Madeira, all in the course of this week, subsequent to the restored energy of sun-spot manifestation and the earth-answering electric cloud of last Sunday, as I wrote to you next day.

Now that, or the first day after the specified occurrence, proved scorchingly hot, with a blue sky and the maximum shade temperature of the season, thus far.

The second day after, a thick screen of clouds was drawn between us and the sun, while the trade-wind was not only restored on the adjacent sea, but with an excess of violence more like that which is felt about Teneriffe: viz, a more southern, and therefore more sun-governed, island.

But the third day after, not only was the sun again totally invisible on account of cloud, but to the surprise of all Madeira there was a heavy, vertical downpour of rain all day long. Old residents protested that they had never, for ten years at least, known anything of the kind at midsummer season. "Precisely so," I replied; " but in the Cape de Verde Islands still further south, and more under solar dominion than even Teneriffe, you will find that every year, the sun coming to the highest northern declination is marked by heavy tropical rains. Wherefore, if Madeira is now visited in the end of June by Cape de Verde solsticial rains, be asstred that the sun is at this moment shining above the clouds over Madeira with much more than his usual annual force."

But though as I write, I would seek to draw the attention of your clever lecturer to unusual solar action being often attended with earth-phenomena which lag behind a few hours only, rather than several years, I do hofe he will also obtain a perusal of my paper of 1869 from the Royal Society, Burlington House, London, and take note of the forty or more year cycle, as well as other shorter ones there alluded to ; for the standard elevenyear cycle, of which we have now begun a new example, will never be completely definable without knowing on each occasion how far the others are mixed up with it. Thus we had, for instance, in August last year, that eleven-year cycle's maximum of temperature which I had pre-announced in print ten years before; but it was very near being lost to observation by occurring not far from the middle of the long-enduring minimum of the forty-five years' cycle, whose prime origin is as certainly solar as that of the eleven-year, and even then much shorter cycles of twelve or fifteen days only, of which I have noted several examples since I have been here.

Piazzr Smyth,

Jones's Hotel, Quinka do Corvalho,

Astronomer-Royal for Scotland

Funchal, Madeira, July 2

\section{Phenomena of Clouds}

THE letter from Prof. Smyth (vol. xxiv. p. 212) recalls to my mind a phenomenon I witnessed several years ago in Arran. I was staying at Strathwhillan, on the north side of Brodick Bay, and looking northward had a full view of Goatfell and Maoldoon. The latter resembles an immense mound heaped up against the eastern side of the former. Snow had recently fallen and coated both. Then a south-easterly wind, coming up and across the firtb, caused a cloud to be formed at a considerable elevation above the hills, having its under surface outlined in correct correspendence with the outlining of the subjacent mountains. This contour the cloud retained in seeming fixity for several hours. I attributed its continued existence to the effects of unequal radiation between the cold snow-covered hills and the warmer moistureladen current above. Whether my surmise was correct, and whether the "central fixity" over Madeira can be referred to the same cause, I leave to the consideration of those more scientifically informed than I.

Cambuslang, July 8

\section{Early English Pendulum Measures}

I FIND in a volume entitled "Metrology, or Weights and Mea:ures of Great Britain and France," by P. Kelly, "Mastex of the Finsbury Square Academy, London,". in 1816 , a list of some of the old pendulum experiments of the last century, which contains some indications quite new to me. I am in hopes that if you will allow me space enough to make them known I may perhaps hear where further information is to be found. One of the measurements which he of course mentions is that of Graham. It is rather strange that though every one of the old writers mentions Graham's experiments confidently, I have hitherto failed to find any account whatever of those experiments. The other observers ment:oned by Kelly-and so far as I know by him only-are "Emerson," "Desaguillieres" [who always wrote under the name of Desaguliers], "Rotherham," and "Sir Jonas Moore." The mention is not a mere hearsay repetition of their names in this connection, as he gives the lingths found by each for London.

In direct connection I may remark that every one knows that the pendulum has been over and over again mentioned and treated as an ultimate appeal in case of failure of other satisfac. tory means of restoring national standards. In fact its earliest use was for this purpose only-except of course in horology. Is it not then a strange thing that it was never-during the whole of the century and a half which so regarded it-used as a medium of comparison of actual national standards? In Graham's time the relation of the French and English units of measure was so uncertain that the pendulum, with all its failings, was quite competent to establish a firmer one. Newton's table 